\title{
Performance Evaluation of MLP and RBF Neural Networks to Estimate the Soil Saturated Hydraulic Conductivity
}

\author{
Elmira Sadat Shams Emamzadeh ${ }^{1}$, Jaber Soltani ${ }^{2}$, Mahmuod Mashal ${ }^{3}$, Moosa Kalanaki ${ }^{4}$ \& Tohid \\ Asadolahzadeh $^{1}$ \\ ${ }^{1}$ M.Sc. of Irrigation \& Drainage Eng., Iran \\ ${ }^{2}$ Assistant Professor of Dept. of Water Eng., College of Abureyhan, University of Tehran, Iran \\ ${ }^{3}$ Associate Professor of Dept. of Water Eng., College of Abureyhan, University of Tehran, Iran \\ ${ }^{4}$ M.Sc. of Artificial Intelligence Eng., Iran \\ Corresponding author: Jaber Soltani, Assistant Professor of Dept. of Water Eng., College of Abureyhan, \\ University of Tehran, Iran. E-mail: jsoltani@ut.ac.ir
}

Received: December 16, 2015

Accepted: August 24, 2016

Online Published: November 10, 2016

doi:10.5539/mas.v11n3p1

URL: http://dx.doi.org/10.5539/mas.v11n3p1

\begin{abstract}
Soil saturated hydraulic conductivity is considered one of the physical soil properties that is very important in modeling of water movement and environmental studies. This study aimed to compare the performance of Multi-Layer Perceptron (MLP) and Radial Basis Function (RBF) in neural networks for estimation of the soil saturated hydraulic conductivity. For this, the data of 27 drilled cased borehole permeameter with three kinds of geometry water flow through the soils and the soil texture properties were used as the input parameters for models. The effectiveness of neural networks to estimate the soil saturated hydraulic conductivity were calculated and compared based on mean squared error (MSE), root mean squared error (RMSE) and coefficient determination $\left(\mathrm{R}^{2}\right)$. According to the above indicators, for all three types of drilled cased borehole permeameter surveyed in this study, the results show MLP neural networks had better performance than RBF neural networks in estimation of the soil saturated hydraulic conductivity and for wells with the horizontal, vertical and horizontal-vertical flow, which the amount of coefficient determination were respectively for all of them 0.94 , 0.97 and 0.85 .
\end{abstract}

Keywords: artificial neural network, cased borehole permeameter, falling head, soil saturated hydraulic conductivity, soil texture

\section{Introduction}

Water can move through soil as saturated flow, unsaturated flow, or vapor flow. Saturated flow takes place when the soil pores are completely filled (or saturated) with water. Saturated hydraulic conductivity describes the speed of movement of water through saturated soil, as well as evaluating and modeling of water, salts and transfer of pollutants to groundwater and environmental studies is widely used and very important. Having information about this parameter for understanding unsaturated zone and development of scientific management in maintaining agricultural productivity and reducing the negative environmental impacts is necessary (Nosrati Karizak et al., 1391, Kurvar et al., 1983, Rinoldzo and Top, 2008). Falling head in cased borehole permeameter method is one of measuring soil saturated hydraulic conductivity method, above the water table. Which was provided by Philip and modified by Reynolds (Philip, 1993, Reynolds, 2010). In order to estimate the saturated hydraulic conductivity, numerical solution of the equations that is presented by Philip and modified by Reynolds is difficult and time consuming (Asadollahzadeh, 2013).

Therefore, artificial neural networks that are powerful tools in machine learning algorithms can be used as an alternative numerical solution.

A neural network model is a conceptual model and in fact, is a simplified image of the mathematical model. The biggest problem faced by users and suppliers of mathematical models, is the need of these models to exact various input data. Artificial neural networks (ANN) which are driven by biological neural networks can help in solving such problems. These networks are a part of the intelligent systems, developed with various spread structures (Chitsazan et al., 2013). Thus, it is possible to process experimental data to identify relationships 
among them and to estimate the amount of saturated hydraulic conductivity (Shakeri Abdolmaleki et al. 2013, Menhaj, 2005). In this respect, the most common neural networks are used Multi Layer Perceptron (MLP)

and Radial Basis Function (RBF) networks (Sarani et al., 2012, Shop \& Liege 1998). Reynolds (2010), developed and evaluated the analysis of falling head cased borehole analysis of Philip in the unsaturated zone. In this study, vertical, horizontal and horizontal-vertical flow were tested in three different forms of water flow. According to the results of this study showed that the developed solutions increased the accuracy of permeameter of falling head in cased borehole. Shop and Liege (1998) did a research on the use of MLP network to estimate the saturated hydraulic conductivity. In this study, four artificial neural network models were used to predict the saturated hydraulic conductivity. The input parameters as follows; The first model (soil textural class), the second model (percentage of sand, silt and clay), the third model (previous model parameters and bulk special density) and fourth model (previous model parameters and moisture content percentage in 0.3 suction). Based on the results of this research, the lowest value for RMSE was reported for the fourth model in forecasting of saturated hydraulic conductivity. Navabian et al. (2004) in the other research estimated the saturated hydraulic conductivity by soil bulk density parameters including apparent especial mass, effective porosity, geometric mean and SD of diameter of particles using Multi-Layer Perceptron (MLP). The results showed that the MLP neural networks are able to estimate the saturated hydraulic conductivity with high accuracy.

Rezaie Arshad et al. (2012) in a study was used of MLP neural networks and regression models to estimate the soil saturated hydraulic conductivity using bulk density, total porosity and soil particle size distribution percentage. The comparison results with MLP showed that the network can more accurately estimate the saturated hydraulic conductivity. ShamsEmamzadeh et al (2014) in a study was used of MLP and RBF to estimate the soil saturated hydraulic conductivity. Comparing both results showed that generally, MLP neural network has a better accuracy. The findings of previous researchers demonstrated that to estimate saturated hydraulic conductivity using easily accessible parameters soil properties like pore size and particle size (grain size) distributions, and soil texture, $\mathrm{pH}, \ldots$ and EC with Multi-Layer Perceptron (MLP). Also, to estimate these parameters is not used of the neural network of Radial Basis Function.

Therefore, the first aim of the present study was to compare the performance of neural networks of Multi-Layer Perceptron (MLP) and Radial Basis Function (RBF) in estimation of the soil saturated hydraulic conductivity. Secondly, in order to explore the possibility of replacing them instead of numerical solution of equation related to falling head of cased borehole permeameter method. For this purpose, the data of 27 drilled cased borehole permeameter with three kinds of geometry water flow through the soils, and the soil texture properties were used as input parameters for the models. The effectiveness of neural networks to estimate the soil saturated hydraulic conductivity were calculated and compared, based on mean squared error (MSE), root mean squared error (RMSE) and coefficient determination $\left(\mathrm{R}^{2}\right)$.

In this study was used of data from of the cased borehole used in the previous research, a case study farm of Tehran University Aboreyhan campus. The characteristics of soil as networks input and soil saturated hydraulic conductivity values which were estimated from the numerical solution of Reynolds equation, As the expected values of this parameters used in the basic analysis. (Asadollahzadeh, 2013). In this study, The ANN models were simulated in MATLAB R2010b software.

\section{Methods and Materials}

\subsection{Study Area}

In this study, field experiments were done at Aboureyhan campus research farm, University of Tehran, located in Pakdasht, $25 \mathrm{~km}$ southeast of Tehran, Iran. The soil texture is loamy in the upper $90 \mathrm{~cm}$. In this work is used of characteristics and data recorded associated to the 27 permeameters of cased borehole with diameters of 4, 6, 8 $\mathrm{cm}$ and various depths where with $1 \mathrm{~m}$ distances in form of regular network were digging in the ground, are used as the input parameters of models.

The saturated hydraulic conductivity of water in soil (or the intrinsic permeability of the soil) can be measured by both field and laboratory experiments. Either way, the experimental measurement of $\mathrm{K}$ (or k) consists in determining the numerical value for the coefficient in Darcy's equation.

In this regard, according to the required parameters in the developed solution by Reynolds, the amounts of physical properties of cased borehole include the radius, height of borehole $(\mathrm{cm})$, water in the wells, soil infiltration, percentage of the constituent particles of soil texture, initial and saturated soil moisture as the input parameters for models were considered.

In order to cover the permeameter of wells, the device consists of a plastic circular consists of a circular tube 
extending to the base of a vertical borehole in an unsaturated soil.

The hydraulic conductivity of a soil is a measure of the soil's ability to transmit water when submitted to a hydraulic gradient. Three types of water flow geometry such as Horizontal, Vertical and Horizontal - Vertical applied into the soil with three replicates and totally 81 cases have been established (Asdollahzadeh.,).

\subsection{Method of Falling Head in Cased Borehole Permeameter}

One of the methods in order to estimate the field saturated hydraulic conductivity is falling-head cased borehole permeameter analysis of Philip.The falling-head lined borehole permeameter (FHBP) consists of a circular tube extending to the base of a vertical borehole in an unsaturated zone, as presented by Philip (1993). The analysis borehole cased falling-head in unsaturated area promoted and investigated.

In this method, there is no need to saturate the soil or water flow to be balanced before the test. Also, With Coating inverse hole and using the falling water head with passing the time in the wells casing and represented formulas, the soil saturated hydraulic conductivity above water table can be estimated.

Philip presented an approximate analytical solution for isotropic heterogeneous soil. Their assumption was that the soil homogeneous and isotropic is heterogeneously non-saturated. (Philip, 1993; Reynolds, 2010).

Philip's Analysis of falling-head of Cased borehole to determine the saturated hydraulic conductivity in unsaturated zone was developed and evaluated by Reynolds. This development ability to use of different modes of water flow geometry and variables of length and radius provides makes.

This geometry consists: 1- vertical flow state (Fig.1, Part A), 2- only horizontal flow state (section of wall permeable to the length L, but the impervious bottom) (Fig. 1, Part B) 3- and a combination of vertical and horizontal flow where the permeable section has the length L (Fig. 1, part C). (In the figures the flow direction is indicated by the arrows).

-The modified and developed Philip's equation is presented on the geometry of flows presented by Reynolds (2010).

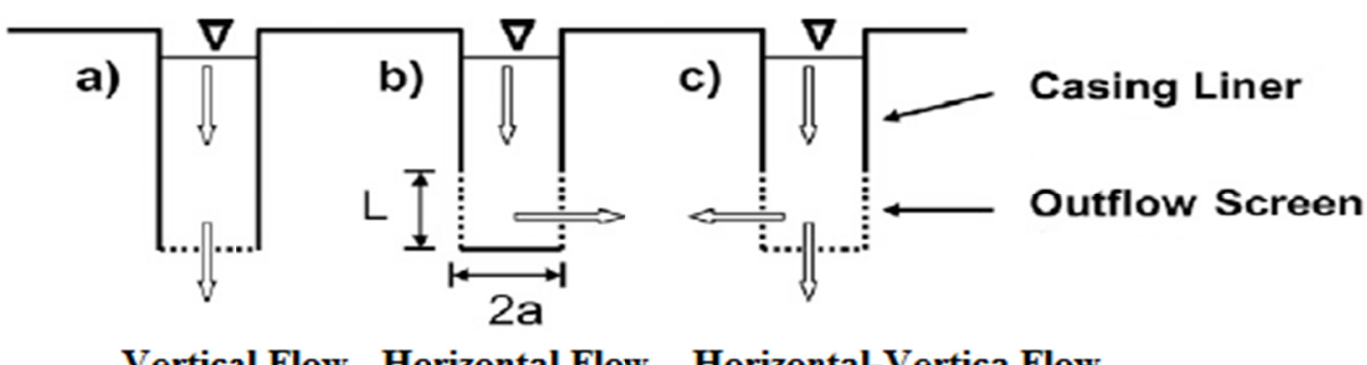

\section{Vertical Flow Horizontal Flow Horizontal-Vertica Flow}

Figure 1. Schematic of flow in cased borehole, provided by Reynolds (2010)

\subsection{Artificial Neural Networks (ANNs)}

In the work of Artificial Neural Networks (ANNs) were used as a tool for modelling non-linear systems. ANNs are simplified as mathematical models of biological. ANNs ability extracted input and output data without any knowledge of process principles (Soltani J. \& Tabari M. R., 2012, Gholamalizadeh et al., 2013).

Therefore, the aim of the present study was to compare the performance of neural networks of Multi-Layer Perceptron (MLP) and Radial Basis Function (RBF) in estimation of the soil saturated hydraulic conductivity.

\subsubsection{Multi-Layer Perceptron (MLP)}

A multi-layered artificial neural network, usually has three types of layers: input, hidden, and output.

In the neural network, first layer called the input layer. The input layer receives input patterns, where the input data was considered and no process actually is done and really the input layer is a transmitter layer.

The last layer is the output layer in which the mapping output vectors deploy and Include those predicted values by the network and provide responses output from the model then introduced the output of the model.

Also, A MLP has a number of middle layer or the hidden layer that is composed of processor neurons. 
The number of layers, number of neurons in each hidden layer and type of the transfer function in each layer normally are determined by trial and error method by network designers (Menhaj, 1384, Abdolmaleki - 2013).

In this study, to train the input data and simulation of artificial neural network is used of supervised learning method.

The Multi-layer perceptron (MLP) networks trained using BP algorithm [Rumelhart et al. ,1986]. Backpropagation algorithm, the most commonly used method is to train multi-layer feedforward networks and there are various methods for training BP algorithm, Methods such as conjugate gradient, quasi-Newton and Levenberg - Marquardt.

The conjugate gradient or the basic backpropagation algorithm adjusts the weights in the steepest descent direction (negative of the gradient). This is the direction in which the performance function is decreasing most rapidly.

Although the function decreases most rapidly along the negative of the gradient, this does not necessarily produce the fastest convergence.

In the conjugate gradient algorithms, a search is performed along conjugate directions, which produces generally faster convergence than steepest descent directions.

In most of the conjugate gradients algorithms, the step size is adjusted in each iteration. Quick optimization in the conjugate gradient method and for minimization problems Newton-type method is one of the ways in which used of quasi-Newton method.

This method is used of second-order derivatives of errors, weights and biases and often converges faster than conjugate gradient method. The Levenberg - Marquardt (LM) algorithm, like Newton's method is designed based on the use of second order derivatives.

Important characteristics of this function is its superfast convergence, that is the fastest known learning algorithm up to now.

Another advantage of this approach is that is not Initially required to determine the rate of learning and algorithms can change the learning rate adaptively in the network (Zoonemat Kermani and Bai, 1392, Demos and Bill, 2002).

In recent work, the Levenberg - Marquart algorithm is used to train the neural network.

The most important unit in neural network structure is their net inputs by using a scalar-to-scalar function called "the activation function or threshold function or transfer function", output a result value called the "unit's activation".

In this research, three of the most widely used transfer functions are used for MLP networks, are used in the neurons structure.

These functions respectively are such as the linear transfer function, equation (1), sigmoid, equation (2) and sigmoid tangent, equation (3) (Kia, 1393).

$$
\begin{gathered}
\operatorname{purelin}(\mathrm{x})=\mathrm{x} \\
\log \operatorname{sig}(\mathrm{x})=\frac{1}{1+\mathrm{e}^{-\mathrm{x}}} \\
\tan \operatorname{sig}(\mathrm{x})=\frac{2}{1+\mathrm{e}^{-2 \mathrm{x}}}-1
\end{gathered}
$$

In which: $\mathrm{x}$ : is an input to the network

The major concern of the designer of an ANN structure is to determine the appropriate number of hidden layers and the number of neurons in each layer.

In order to achieve the best network structure in MLP network architecture, was used of the trial and error procedure using to determine an optimum the transfer layer functions, the number of neurons in the hidden layers during training. Also in this research, is the method used. Ebberhart and Dobbins (1990) suggested starting with hidden nodes equal to half of the input nodes. Tingsanchali and Gauatam (2000) found that starting with hidden nodes equal to or slightly greater than the input nodes is adequate (Wen Wang, 2000).

In this regard, the number of hidden layers and double-layers and the number of neurons were considered between 2 and 50 . 
In general, adjacent layers of neurons in each layer to all neurons are linked by a directional relationship and data can be transmitted between neurons through these connections.

Each of these connection links has its own specific weights are multiplied by transmitted information from one neuron to another neuron.

Firstly, an artificial Neural network must be trained to do a thing. Generally, An ANN consists of nodes in different layers; input layer, intermediate hidden layer(s) and the output layer. The connections between nodes of adjacent layers have "weights" associated with them. The goal of learning is to assign correct weights for these edges. In other words, the basis of the training network, is the process of determining the arc weights that in fact are the key elements of a Neural Network. Given an input vector, these weights determine what the output vector is.

In general, the process of training and determining the network weight and bias is performed based on $70 \%$ of the measured data random selection was used, then the model with about 10 percent of the records is validated.

Finally, about $20 \%$ of samples in order to test and evaluate the ability to generalize the model (Menhaj, 1384, Soltani et $\mathrm{Al}$ 2012).

Finally, in order to evaluate the generalization ability of the trained ANN model on unseen data, about $20 \%$ of samples in order to test and evaluate was used (Menhaj, 1384).

\subsubsection{Radial Basis Function Network (RBFN)}

Radial Basis Function Network (RBFN) correspond to a particular class of function approximators which can be trained, using a set of samples. RBFNs have been receiving a growing amount of attention since their initial proposal [Broomhead and Lowe,1988, Moody and Darken,1988], and now a great deal of theoretical and empirical results is available. The RBFNs is widely used to estimate the non-parametric multi-dimensional functions via a limited series of educational information.

RBF networks have three layers: input layer, hidden layer and output layer. One neuron in the input layer corresponds to each predictor variable. With respects to categorical variables, $n-1$ neurons are used where $\mathrm{n}$ is the number of categories. Hidden layer has a variable number of neurons. Each neuron consists of a radial basis function centered on a point with the same dimensions as the predictor variables. The output layer has a weighted sum of outputs from the hidden layer to form the network outputs.

These networks are most inspired by statistical techniques models classification. RBFNs and statistical techniques have been used in a large number of areas.

These networks are a type of feedforward neural networks and structurally similar to MLP networks.

MLP and RBFN of types are the most widely used neural network models for practical applications. But compare between MLP \& RBFNs shows that the MLP belong to a group of "classical" neural networks (whose weighted sums are loosely inspired by biology), while, the RBFN is based on analogy to regression theory (Broomhead \& Lowe 1988).

The main difference of RBFNs with MLP networks is on the number of hidden layers, input vector type and transfer function.

The RBFNs networks only have a middle layer and function of neurons triggers, radial functions with center and specific width.

Moreover, contrary to the network back propagation of error in which sum of the weighted neuron -received by the intermediate hidden layer neurons as input activation function are calculated.

Here, the distance between each pattern with the vector of each vector in the middle layer as input of radial actuation function are calculated (Dehghani et al., 1389, Vaziri, 1385).

In this method, stimulus function is the radial function in the middle layer, and linear function in the output layer. In this network, input signals are directly entered into the hidden layer neurons.

Unlike MLP networks with public activity functions, the activity functions are local in these networks.

The number of hidden layer neurons is obtained from trial and error method.

At the output layer, only the picker is available that its entrances are the hidden layer neurons output.

The number of neurons in the output layer are equal to the number of outputs.

This network according to its various applications, has become one of the most famous neural networks and 
most important competitor of the MLP neural network (Bayat and Najafi, 1392, Vaziri, 1385).

\section{Data Preprocessing}

In the preprocess stage, data for integration of the impact of inputs used for models output and increase of models function, before the usage of input data, first of all using the linear method of normalization, total data were taken into interval $[-1,1]$, EQ.4

$$
\mathrm{X}_{\mathrm{n}}=2 *\left(\frac{\mathrm{x}-\mathrm{X}_{\min }}{\mathrm{x}_{\max }-\mathrm{X}_{\min }}\right)-1
$$

In which:

X: observational data

Xmax: maximum observational data for the desired parameter

Xmin: the minimum observational data for the desired parameter

$\mathrm{Xn}$ : the normalized data.

it is required to be mentioned that in this research, the units used to all parameters of length and time, respectively are meter and second.

\section{Accuracy Evaluation Criteria}

In this study, the index of coefficient of determination (R2), mean squared error (MSE) and root mean square error (RMSE) is designed to assess the accuracy and efficiency of the models to estimate the amount of soil saturated hydraulic conductivity.

$$
\begin{gathered}
R^{2}=\frac{\left[\sum_{i=1}^{N}\left(K_{p_{i}}-\bar{K}_{p}\right) \cdot\left(K_{o_{i}}-\bar{K}_{o}\right)\right]^{2}}{\sum_{i=1}^{N}\left(K_{p_{i}}-\bar{K}_{p}\right)^{2} \cdot\left(K_{o_{i}}-\bar{K}_{o}\right)^{2}} \\
M S E=\frac{1}{N} \sum_{i=1}^{N}\left(K_{o_{i}}-K_{p_{i}}\right)^{2} \\
R M S E=\sqrt{\frac{1}{N} \sum_{i=1}^{N}\left(K_{o_{i}}-K_{p_{i}}\right)^{2}}
\end{gathered}
$$

In which:

$K_{o_{i}}$ : expected values of soil saturated hydraulic conductivity, for i-th sample

$K_{p_{i}}$ : predicted values of saturated hydraulic conductivity for the i-th sample by Neural Network

$\bar{K}_{o}$ : the average of expected values of soil saturated hydraulic conductivity

$\bar{K}_{p}$ : the average of predicted values of soil saturated hydraulic conductivity by artificial neural network.

\section{Results and Discussion}

For each category, the data intended for Cased borehole permeameter with the horizontally, vertically and horizontally - vertically of flow, MLP and RBF neural network structure was formed.

For MLP networks in the selection of number of hidden layers, number of neurons in layers and transfer functions was used of trial and error method.

Among the performances were taken, the best results for each of the three streams were recorded and presented in Table.1.

In these networks, error function and education function for data of all three types of flows, respectively are MSE (Mean Squared Error) and trainlm (Levenberg-Marquart function). 
Table 1. The structure of the MLP networks and the accuracy of the results of data in the three types of flow

\begin{tabular}{|c|c|c|c|c|c|c|c|c|}
\hline Flow & $\begin{array}{l}\text { Input } \\
\text { Layer }\end{array}$ & $\begin{array}{l}\text { First Hidden } \\
\text { Layer }\end{array}$ & $\begin{array}{l}\text { Second Hidden } \\
\text { Layer }\end{array}$ & $\begin{array}{l}\text { Output } \\
\text { Layer }\end{array}$ & Data & $\mathrm{R}^{2}$ & MSE & RMSE \\
\hline Horizontal & 10 & $\begin{array}{c}8 \\
\text { tansig }\end{array}$ & $\begin{array}{c}14 \\
\operatorname{logsig}\end{array}$ & $\begin{array}{c}1 \\
\text { purelin }\end{array}$ & $\begin{array}{c}\text { Training } \\
\text { Validation } \\
\text { Test }\end{array}$ & $\begin{array}{l}0.951 \\
0.926 \\
0.940\end{array}$ & $\begin{array}{l}0.033 \\
0.051 \\
0.038\end{array}$ & $\begin{array}{l}0.180 \\
0.226 \\
0.196\end{array}$ \\
\hline Vertical & 10 & $\begin{array}{c}9 \\
\operatorname{logsig}\end{array}$ & $\begin{array}{c}7 \\
\text { tansig }\end{array}$ & $\begin{array}{c}1 \\
\text { purelin }\end{array}$ & $\begin{array}{c}\text { Training } \\
\text { Validation } \\
\text { Test }\end{array}$ & $\begin{array}{l}0.989 \\
0.977 \\
0.969\end{array}$ & $\begin{array}{l}0.004 \\
0.010 \\
0.018\end{array}$ & $\begin{array}{l}0.065 \\
0.101 \\
0.069\end{array}$ \\
\hline $\begin{array}{l}\text { Vertical-Hor } \\
\text { izontal }\end{array}$ & 10 & $\begin{array}{c}10 \\
\operatorname{logsig}\end{array}$ & -------- & $\begin{array}{c}1 \\
\text { purelin }\end{array}$ & $\begin{array}{c}\text { Training } \\
\text { Validation } \\
\text { Test }\end{array}$ & $\begin{array}{l}0.844 \\
0.817 \\
0.846\end{array}$ & $\begin{array}{l}0.073 \\
0.065 \\
0.071\end{array}$ & $\begin{array}{l}0.270 \\
0.256 \\
0.266 \\
\end{array}$ \\
\hline
\end{tabular}

In the following, the results exit from the normal state and curves representing the expected values of soil saturated hydraulic conductivity and its estimated values by MLP networks for test samples related to the horizontal, vertical and horizontal-vertical water flow, respectively, were presented in the figures of (2) to (4).

These graphs represent performance of the network in the saturated hydraulic conductivity of study area anticipation as well.

Evaluation of charts and tables accuracy assessment indicators show that the highest accuracy of models to estimate the soil saturated hydraulic conductivity, is related to the obtained model for data belonged to the wells with a vertical water flow.

Then, we have a horizontal flow and ultimately the weakest performance data is related to horizontal - vertical compound flow.

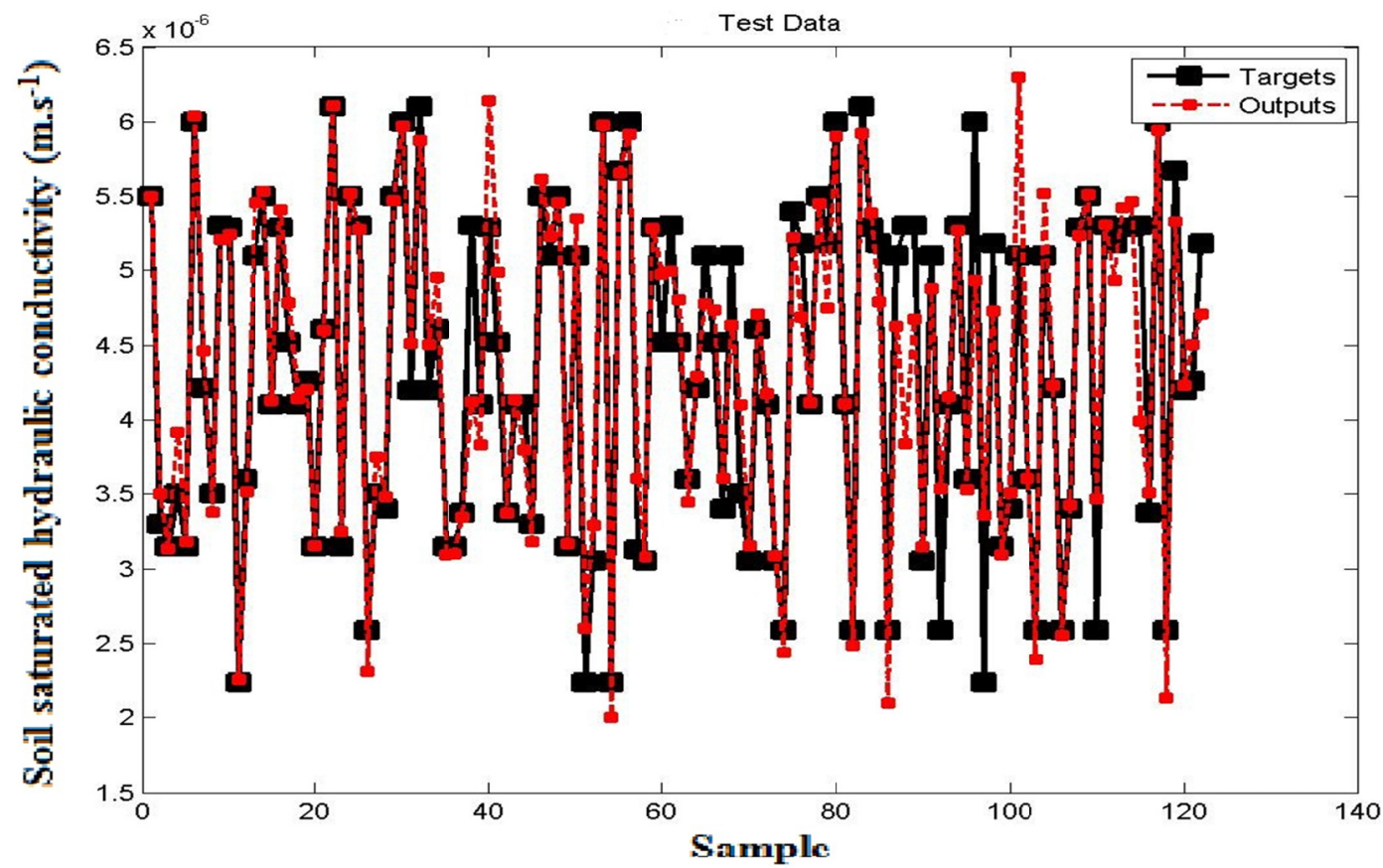

Figure 2. Actual and estimated values of saturated hydraulic conductivity by MLP neural network for test data of the horizontal flow 


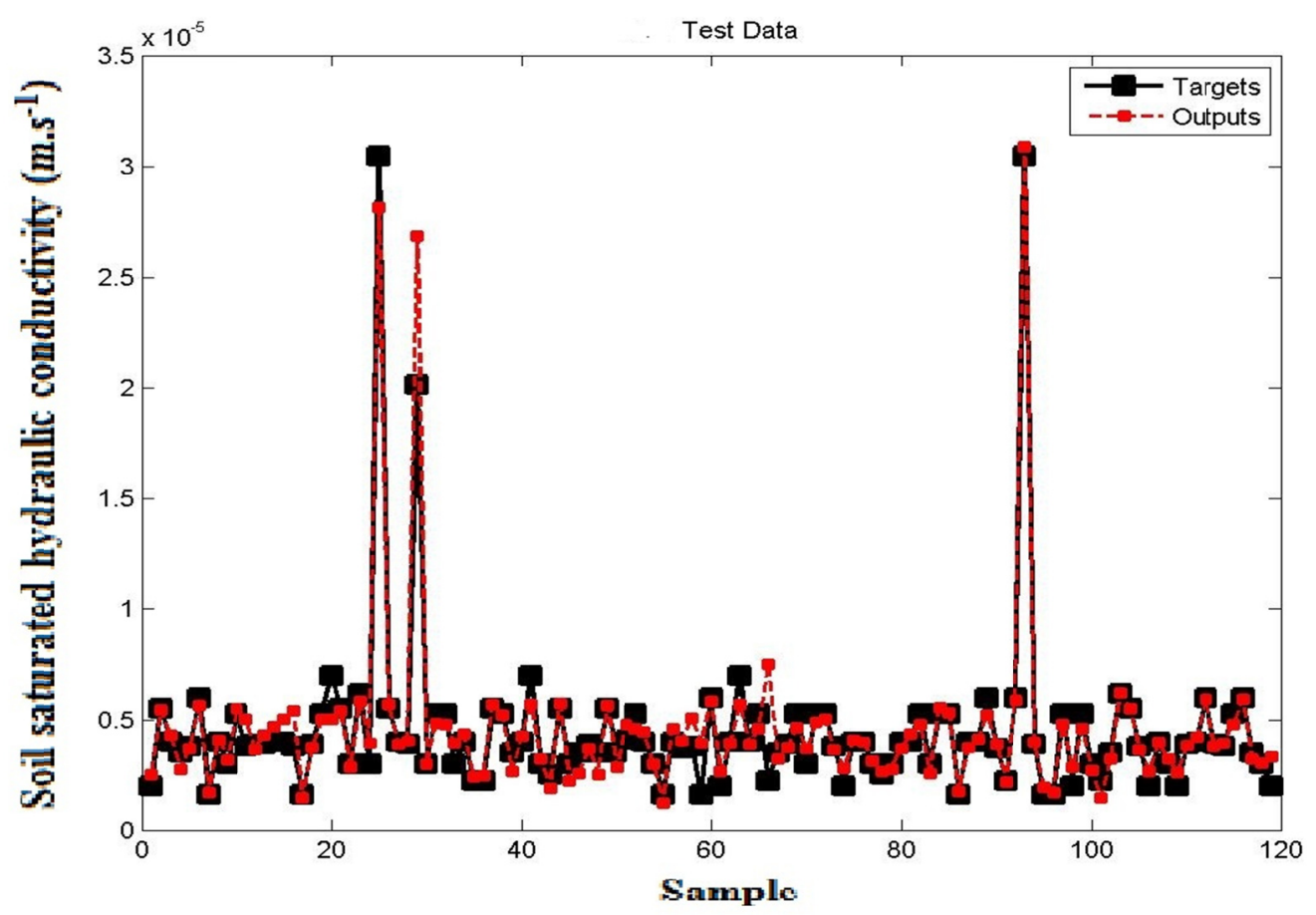

Figure 3. Actual and estimated values of saturated hydraulic conductivity by MLP neural network for test data of the vertical flow

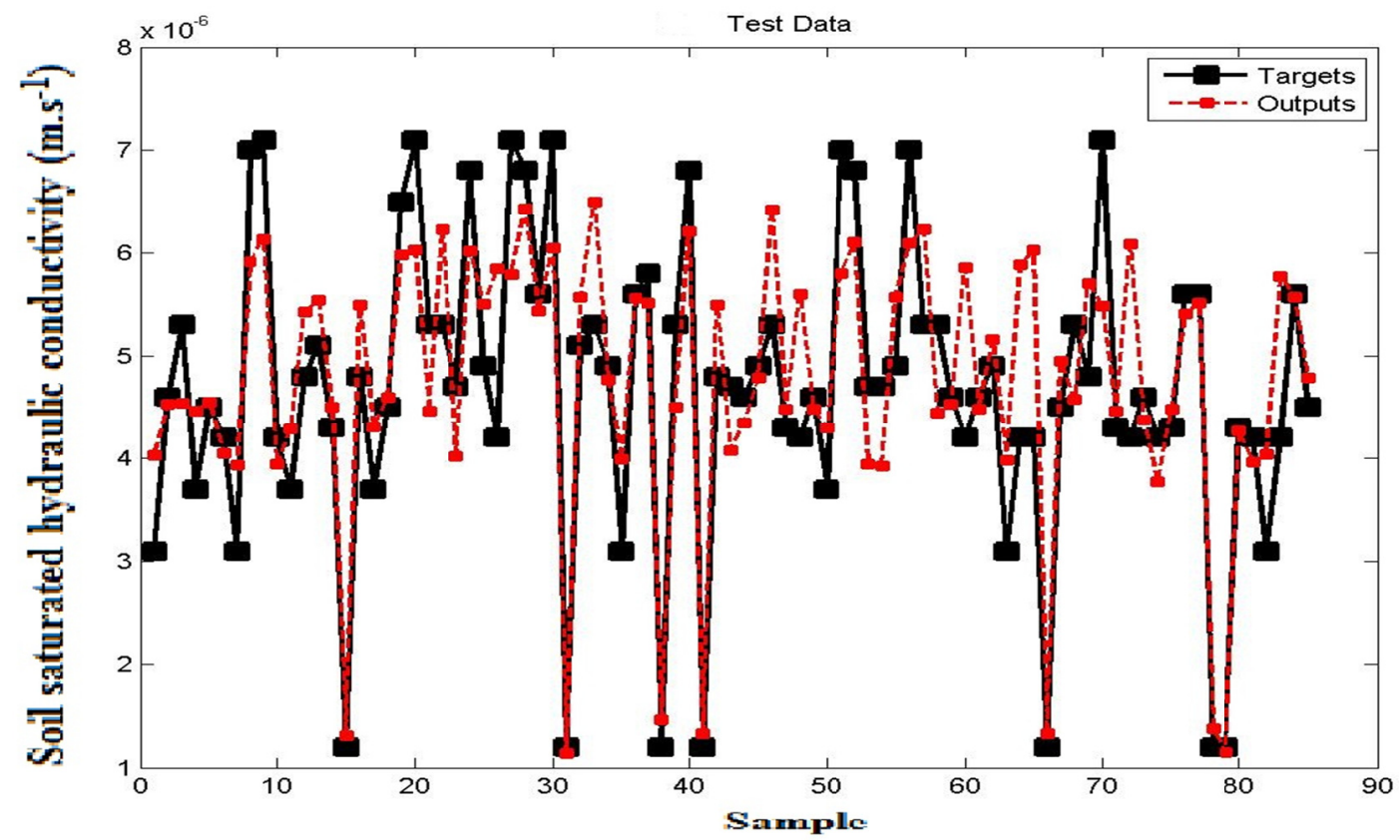

Figure 4. Actual and estimated values of saturated hydraulic conductivity by MLP neural network for test data of the vertical-horizontal flow

Radial Basis Function for neural network according to the network structure, is the number of hidden layers of a layer.

It was only necessary to determine the number of neurons in the hidden layer of the network for each of the three types of mentioned flow. The achieved results are provided for each of the categories of data in the table (2). 
Table 2. The structure of the RBF networks and the accuracy of the results of their performance for the three types of flow

\begin{tabular}{|c|c|c|c|c|c|c|c|}
\hline Flow & Input Layer & Hidden Layer & Output Layer & Data & $\mathrm{R}^{2}$ & MSE & RMSE \\
\hline \multirow[t]{3}{*}{ Horizontal } & \multirow[t]{3}{*}{10} & \multirow{3}{*}{$\begin{array}{c}48 \\
\text { radbas }\end{array}$} & \multirow{3}{*}{$\begin{array}{c}1 \\
\text { purelin }\end{array}$} & Training & 0.902 & 0.064 & 0.254 \\
\hline & & & & Validation & 0.919 & 0.052 & 0.228 \\
\hline & & & & Test & 0.884 & 0.069 & 0.262 \\
\hline \multirow{3}{*}{ Vertical } & \multirow[t]{3}{*}{10} & \multirow{3}{*}{$\begin{array}{c}22 \\
\text { radbas }\end{array}$} & \multirow{3}{*}{$\begin{array}{c}1 \\
\text { purelin }\end{array}$} & Training & 0.963 & 0.014 & 0.118 \\
\hline & & & & Validation & 0.961 & 0.021 & 0.144 \\
\hline & & & & Test & 0.948 & 0.020 & 0.142 \\
\hline \multirow[t]{3}{*}{ Vertical-Horizontal } & \multirow[t]{3}{*}{10} & \multirow{3}{*}{$\begin{array}{c}42 \\
\text { radbas }\end{array}$} & \multirow{3}{*}{$\begin{array}{c}1 \\
\text { purelin }\end{array}$} & Training & 0.822 & 0.070 & 0.264 \\
\hline & & & & Validation & 0.865 & 0.085 & 0.292 \\
\hline & & & & Test & 0.829 & 0.096 & 0.310 \\
\hline
\end{tabular}

In the following, results from un-normal state and curves represent the expected values of soil saturated hydraulic conductivity and estimated values by neural network and Radial Basis Function, for test examples related to horizontal, vertical and horizontal - vertical water flow data were presented respectively in the Figures (5) to (7).

This graphs well represents the networks performance in the anticipation of saturated hydraulic conductivity in the study area.

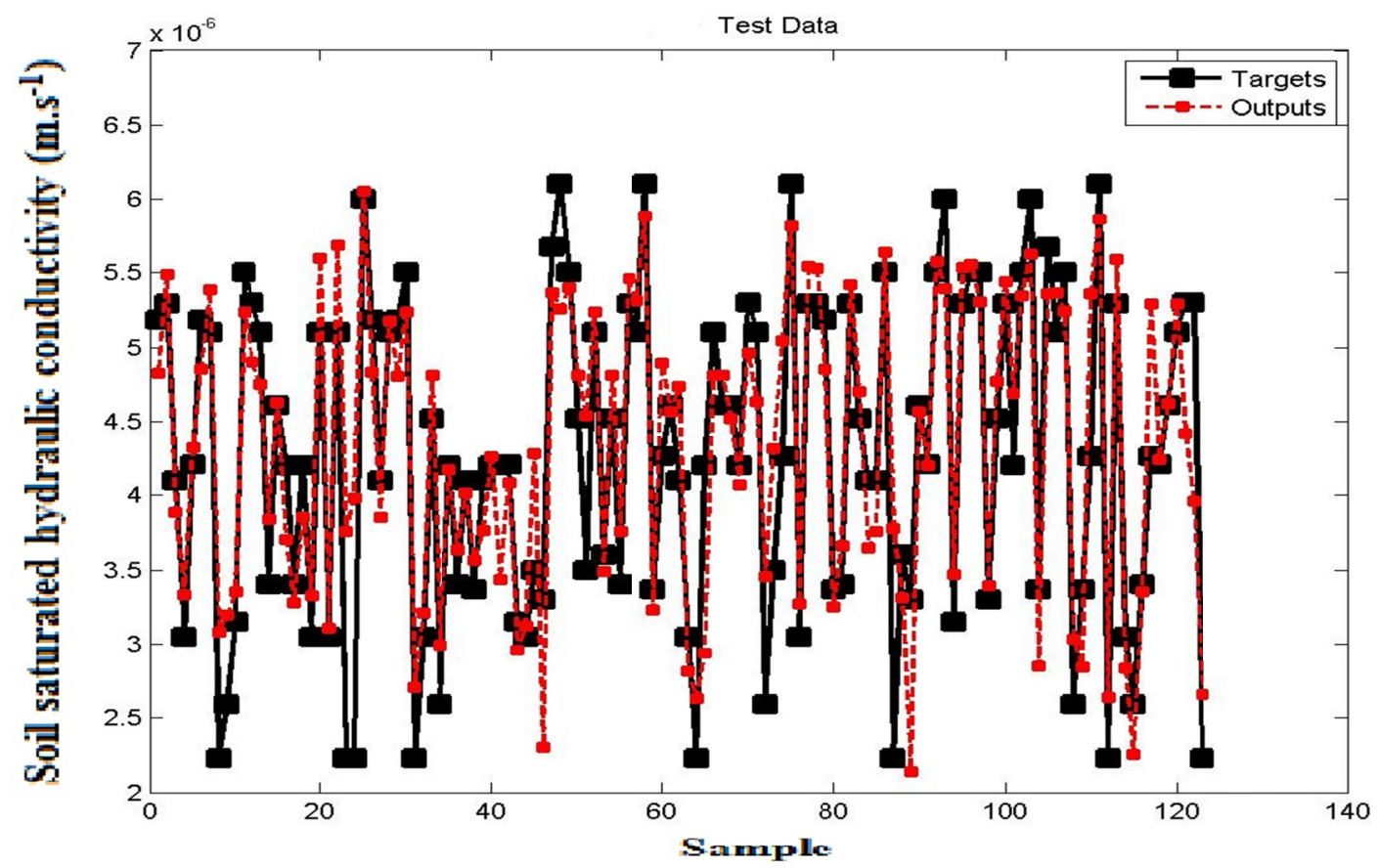

Figure 5. Actual and estimated values of saturated hydraulic conductivity by RBF neural network for test data of the horizontal flow 


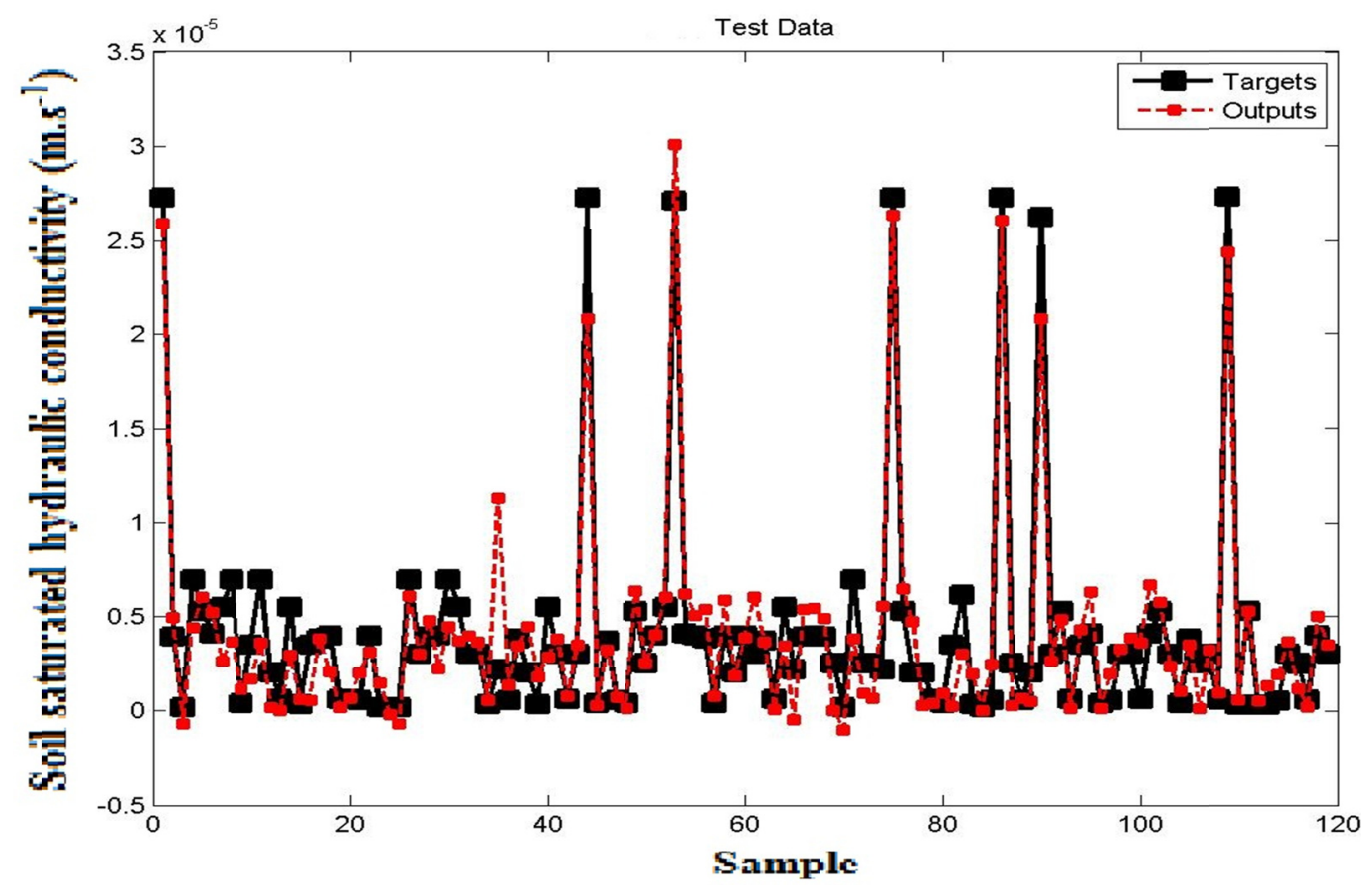

Figure 6. Actual and estimated values of saturated hydraulic conductivity by RBF neural network for test data of the vertical flow

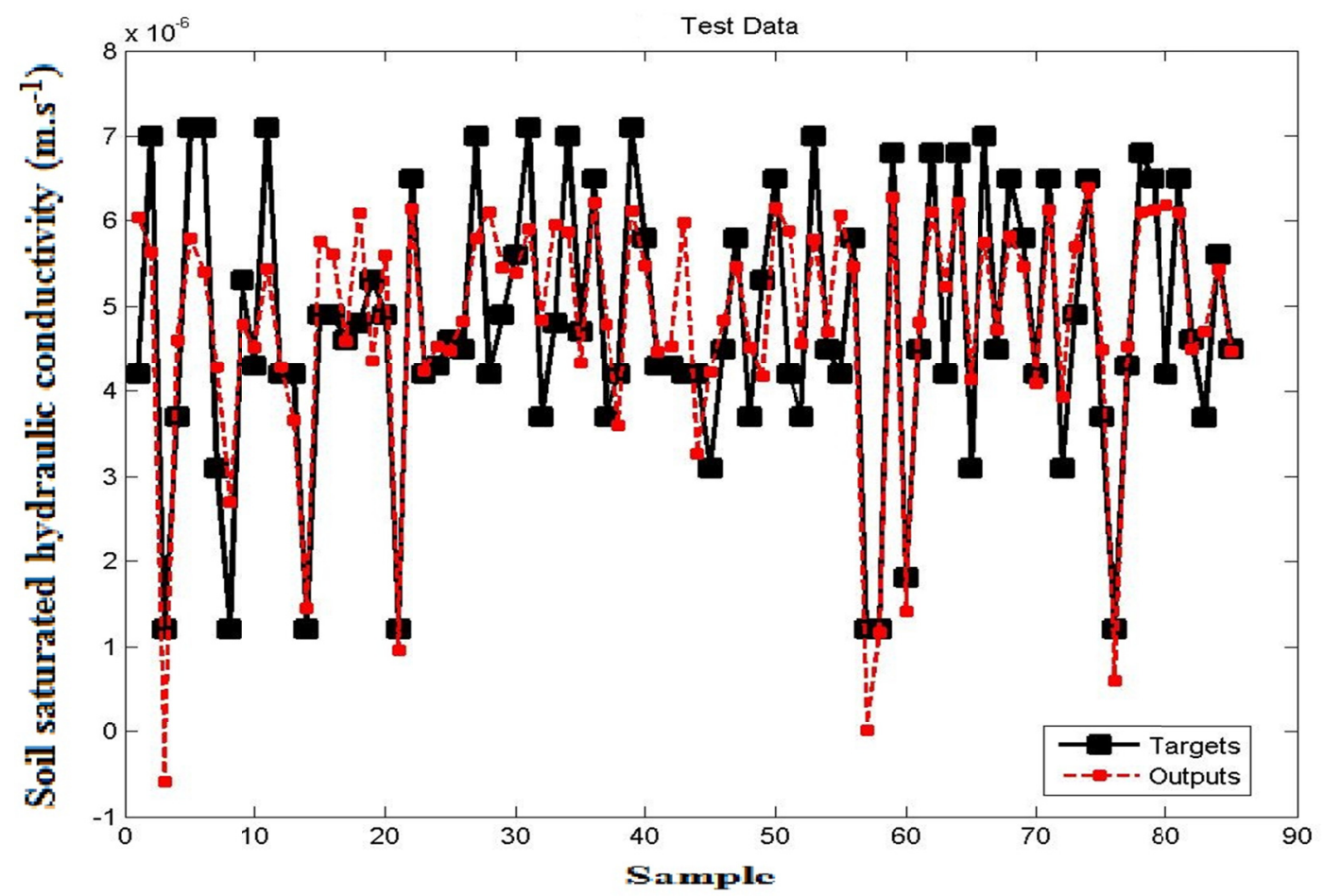

Figure 7. Actual and estimated values of saturated hydraulic conductivity by RBF neural network for test samples of the data in horizontal - vertical flow

Survey results ccareful evaluation of all Charts and Tables of indexes values of network performance evaluation of base radius for the test samples related to three types of flow show that the best performance of the network, is owned by the vertical flow data. After that the performance related to the horizontal flow is considered and the 
weakest results is related to the combined horizontal - vertical flow.

\section{Conclusion}

This study was conducted to investigate and evaluate the performance of MLP and RBFN for data of each of three cased borehole permeameter with flow horizontal, vertical and horizontal - vertical flow of water by error-indices.

Although, study results based on determination coefficient values and error indexes defined per test samples show that,

Both types of networks have been able to some extent acted with reasonable accuracy and be as a good alternative for Numerical Solution developed by Reynolds,

But generally, for test samples of each of three cased borehole permeameter, MLP network performance in the estimation of soil saturated hydraulic conductivity compared with RBF network have been a better performance.

These networks have been able to estimate saturated hydraulic conductivity with less MSE and RMSE indexes and more determination coefficients values.

Based on resulting coefficients of determinations (R2), for all three types of drilled cased borehole permeameter surveyed in this study, the results show MLP neural networks had better performance than RBF neural networks in estimating the soil saturated hydraulic conductivity and for wells with the horizontal, vertical and horizontal-vertical flow, which the amount of coefficient determination were $0.94,0.97$ and 0.85 respectively.

Among the results of the research is observed that the MLP networks for estimation of saturated hydraulic conductivity of three types of cased boreholes, the best performance was for wells with vertical flow with the determination coefficient about 0.97 .

Then, respectively, the wells with horizontal flow and combined horizontal-vertical flow by resulting coefficients of determinations (R2) are 0.94 and 0.85 .

In addition, in this study for the number of equal input parameters, the MLP network structure compared with RBF networks, the number of neurons used were less and performance accuracy is higher.

The requirement for fewer neurons (processing units) in the network can be supposed as another reason of the superiority and power of MLP networks in estimation of hydraulic conductivity of saturation of soil based on the desired inputs.

\section{References}

Asadollahzadeh, T. (2013). Measuring field saturated hydraulic conductivity and absorptive number using these methods by cased boreholes permeameters methods and evaluation HYDRUS-2D model. Master's Thesis in water resources Engineering, College of Abureyhan, University of Tehran, Tehran, Iran. (in Persian)

Bayati, H., Najafi, A. (2013). Performance Comparison Artificial Neural Networks with Regression Analysis in Trees Trunk Volume Estimation. Iranian Journal of Forest and Poplar Research, 20, 4(50), 595-607. (in Persian)

Broomhead, D. S., \& Lowe, D. (1988). Multivariable Functional Interpolation and Adaptive Network. Complex System, 2, 321-355.

Deghani, A., Piri, M., Hesam, M., \& Dehghani, N. (2010). Estimation of daily pan evaporation by using MLP, RBF and Elmani Neural Networks. Journal of Water and Soil Conservation, 17(2), 49-69. (in Persian)

Demuth, H., \& Beale, M. (2002). Neural Network Toolbox User's Guide. Version 4. The Math Works, Inc. Retrieved from http://www.mathworks.com

Emamzadeh, S., Soltani, A. S. J., Mashal, M., \& Kalanaki, M. (2014). Comparison of RBF and MLP neural network performance to estimate the saturated hydraulic conductivity. Second National Conference on Sustainable Agriculture and Natural Resources.

Gholamalizadeh, A. A., Soltani, J., \& Shakeri, A. A. R. (2013). Predicting Mn concentration in water reservoir using Artificial neural network (Chahnimeh1reservoir, Iran). International Journal of Agriculture and Crop Sciences, 6, 20(2013), 1413-1420.

Kia, S. M. (2014). Neural Networks in MATLAB. Third edition. University of Gilan Publications, Gilan. 408 pages. (in Persian)

Koorevaar, P., Menelik, G., \& Dirksen, C. (1983). Elements of soil physics. Elsevier, New York, 228 p. 
Mehre Arvand Institution of Higher Learning Eco-Friendly Promotional Group. (2016). Retrieved from http://www.civilica.com/Paper-NACONF02-NACONF02_0913.html. (in Persian)

Menhaj, M. B. (2005). Principles of Neural Networks (Computational Intelligence). Third Edition, Amir Kabir Academic publications center, Tehran, p. 718. (in Persian)

Navabian, M., Liaghat, A., \& Homaee, M. (2004). Quick estimate saturated hydraulic conductivity using artificial neural network. Proceedings of the Third Technical workshop on drainage and environment. Tehran, IRAN. National Committee on Irrigation and Drainage. Retrieved from http://www.civilica.com /Paper-WDEE03-WDEE03_009.html (in Persian)

Nosrati, K. F., Movahedi, S. A., Naini, A. Hezar, J., Rishani, Gh. A., \& Dehghani (2012). Using artificial neural networks to estimate saturated hydraulic conductivity from easily available soil properties. Electronic Journal of Soil Management and Sustainable Production, 2(1), 95-110. (in Persian)

Philip, J. R. (1993). Approximate analysis of falling-head lined borehole permeameter. Water Resources Research, 29(11), 3763-3768.

Reynolds, W. D. (2010). Measuring soil hydraulic properties using a cased borehole permeameter: Steady flow analyse. Vadose Zone, 10, 999-1015.

Reynolds, W. D., \& Topp, G. C. (2008). Soil water analyses: Principles and parameters. In M.R. Carter, \& E.G. Gregorich (Eds.), Soil sampling and methods of analysis. 2nd Ed. CRC Press, Boca Raton, FL. pp. 913939.

Rezaei, A. R., Sayad, G. A. Mazloom, M., Jafari N., \& M. Shorafa, 2012, Comparison of artificial neural networks and regression pedotransfer functions for predicting saturated hydraulic conductivity in soils of Khuzestan province. JWSS - Isfahan University of Technology, 16(60), 107-118. (in Persian)

Rumelhart, D. E., Hinton, G. E., \& Williams, R. J. (1986). Learning Representations by Back- Propagating Errors. Nature, 323, 533-536.

Sarani, N., Soltani, J., Sarani, S., \& Moasheri, A. (2012). Comparison of Artificial Neural Network and Multivariate Linear Regression Model to Predict Sodium adsorption ratio (SAR) (Case Study: Sistan River, Iran). International Conference on Chemical, Ecology and Environmental Sciences (ICEES'2012) Bangkok, 130-134.

Schaap, M. G., \& Leij, F. J. (1998). Using neural networks to predict soil water retention and soil hydraulic conductivity. Soil and Tillage Research, 47, 37-42.

Shakeri, A. A., Gholamalizadeh, A. A., \& Soltani, J. (2013). Artificial neural network (ANN) approach for predicting $\mathrm{Cu}$ concentration in drinking water of Chahnimeh1 Reservoir in Sistan-Balochistan, Iran. Journal of Health Scope Quarterly, Health Scope, 2(1), 31-8.

Soltani, J., \& Tabar, M. M. R. (2012). Determination of Effective Parameters in Pipe Failure Rate in Water Distribution System Using the Combination of Artificial Neural Networks and Genetic Algorithm. Journal of Water and Wastewater, 23(3), 2-15. (In Persian)

Vaziri, M. (2006). The position estimation methods for internal environments using radial circuit neural networks. Amirkabir University of Technology. Tehran. Master's thesis. (in Persian)

Wen, W. (2006). Stochasticity, Nonlinearity and Forecasting of Streamflow Processes. Retrieved from https://books.google.com/books?isbn=1586036211- Technology \& Engineering

Zoonemat, K. M., Bai, Y. M. (2013). Efficiency analysis of artificial neural networks and multiple linear regression methods for tides prediction. Journal of Oceanography, 10(13), 1-10. (in Persian)

\section{Copyrights}

Copyright for this article is retained by the author(s), with first publication rights granted to the journal.

This is an open-access article distributed under the terms and conditions of the Creative Commons Attribution license (http://creativecommons.org/licenses/by/4.0/). 